\title{
V Jornada de Enfermagem do INCA
}

\author{
"A Ciência e a Arte de Cuidar"
}

Data: 24 e 25 de agosto de 2006

Local: Instituto Nacional de Câncer

ORGANIZAÇÃO

Coordenação de Ensino e Divulgação Científica (CEDC) e Comissão de Ensino de Enfermagem do INCA

\section{Resumos}




\title{
Câncer de cólon em criança: um desafio para a enfermagem
}

\author{
Isabelle Pimentel Gomes, Paula Elaine Diniz dos Reis
}

O câncer de cólon ocorre freqüentemente em adultos. Devido à raridade desse tipo de câncer em criança, este é quase sempre diagnosticado em estágio avançado, pois quando as queixas abdominais ocorrem são confundidas com afecções comuns na infância. É necessária a quimioterapia para o tratamento de tumores em estágios III ou IV; naqueles operados com doença T3 ou T4 e/ou com linfonodos comprometidos pela doença, o intuito é adjuvante. Os enfermeiros oncologistas pediátricos não estão habituados a administrar as medicações utilizadas nos esquemas quimioterápicos usados para essa doença. Com o objetivo de subsidiar um cuidado de enfermagem qualificado no tratamento de crianças com câncer de cólon e identificar evidências efetivas para o controle dos efeitos colaterais das medicações, realizou-se uma revisão de literatura, na qual foram selecionados os esquemas mais indicados atualmente, e traçado um plano de cuidados. As medicações mais utilizadas são fluorouracil, leucovorin, oxaliplatina e irinotecano. O estudo pode auxiliar os enfermeiros oncologistas pediátricos a obter informaçōes sobre as medicações, os efeitos colaterais e os cuidados de enfermagem; e serve como orientação os enfermeiros para um cuidado qualificado diante do desafio de assistir uma criança com câncer de adulto.

E-mail: enfisabelle@yahoo.com.br 


\title{
Comportamento preventivo frente ao câncer do colo uterino entre mulheres trabalhadoras de uma Região Noroeste do Estado do Paraná
}

\author{
Andréia Cristiane Pizani Domingos, Iris Maria Hiray Murata , Sandra Marisa Pelloso, Janine Schirmer
}

\begin{abstract}
Objetivou-se verificar o comportamento preventivo de mulheres trabalhadoras quanto ao câncer do colo uterino e identificar fatores associados à realização ou não do exame Papanicolaou. Trata-se de estudo descritivo exploratório, utilizando questionário auto-aplicado, envolvendo 116 mulheres. Os resultados revelaram a predominância de trabalhadoras na faixa etária entre 20 anos e 39 anos (77,6\%); que têm companheiro (95,6\%); com nível médio de escolaridade (67,5\%); renda familiar de 3 a 4 salários-mínimos (50,0\%); iniciaram atividade sexual com 18 anos ou menos (50,0\%) e com mais de 18 anos (40,5\%); referiram apenas um parceiro sexual nos últimos 12 meses (81,0\%), porém, apenas 26,7\% fazem uso de preservativo (condon) durante as relaçóes sexuais. Tiveram 2 partos ou menos $(47,4 \%)$ e 46,5\% são nulíparas. Quanto à realização do exame de Papanicolaou, 46,5\% realizam-no anualmente, e 57,7\% realizam-no na rede não-SUS devido aos horários de atendimento da rede SUS igual ao horário de trabalho, mau atendimento e demora no atendimento. Entre as mulheres que relataram nunca terem realizado o exame, os motivos foram medo, descuido, comodismo, timidez, falta de tempo, não ter apresentado nenhum problema ainda, falta de vaga e indisponibilidade de horário na rede SUS. Pelos resultados obtidos, observa-se a necessidade de reforçar orientações que valorizem o desenvolvimento de hábitos de prevenção dessa neoplasia, bem como promover meios, junto às instituiçôes públicas de saúde, que possibilitem o acesso das mulheres trabalhadoras à realização periódica de prevenção e controle do câncer ginecológico.
\end{abstract}

E-mail:imhmurata@uem.br 


\title{
Associação entre qualidade de vida e conforto de pessoas com câncer avançado em cuidados paliativos em domicílio*
}

\author{
Silvana dos Santos Barreto, Eloita Pereira Neves
}

Trata-se de um estudo qualitativo, descritivo, realizado com pacientes com câncer avançado em Cuidados Paliativos atendidos em domicílio. Os objetivos foram identificar o nível de conforto e de qualidade de vida das pessoas com câncer avançado; compreender as razões apontadas pelas pessoas em relação ao seu nível de conforto e de qualidade de vida; identificar os padróes de associação entre qualidade de vida e conforto para as pessoas com câncer avançado. A coleta de dados foi realizada durante a consulta de enfermagem por meio de entrevista semi-estruturada. A análise dos resultados mostrou que os participantes descrevem o conforto como sensação de segurança/proteção, cuidado, comodidade e de ter sua integridade preservada. Já a qualidade de vida como sensação de bem-estar físico-psico-social. É possível compreender que o padrão de bem-estar se refere à sensação experienciada pela pessoa que se sente segura, protegida, amparada, apoiada, cuidada e desfruta de relaçôes satisfatórias com as outras pessoas - familiares, amigos, profissionais - e é capaz de realizar um mínimo de atividades.

E-mail: sil_barreto@yahoo.com.br

\footnotetext{
* Extraído da Dissertação de Mestrado em Enfermagem: "Associação entre qualidade de vida e conforto de pessoas com câncer em cuidados paliativos em domicilio, na compreensão do enfermeiro" apresentada à Universidade do Estado do Rio de Janeiro.
} 


\title{
Integração ensino-serviço no atendimento ao paciente com câncer
}

\author{
Carla Maria Castro dos Santos, Maria Helena dos Santos Batista Borges, Noélia Silva Oliveira，Sônia Maria Isabel Lopes Ferreira
}

\begin{abstract}
A educação em enfermagem oncológica pressupóe o desenvolvimento de processos de mudanças no conhecimento, na normatização de práticas adotadas, na habilidade de comunicação com o paciente de câncer e seus familiares. Nesse sentido, estabeleceu-se parceria da Coordenação de Enfermagem do CACON de Itabuna (BA) com os Projetos de Extensão, Educação Continuada, Prevenção e Controle de Infecção Hospitalar e Discentes do Curso de Enfermagem da Universidade Estadual de Santa Cruz (UESC), em Ilhéus (BA). O objetivo do trabalho é relatar as ações desenvolvidas nessa parceria. Desenvolvemos ações educativas com o paciente e sua família; orientação ao autocuidado e cuidadores; reunióes científicas com ênfase nos tumores sólidos e seus respectivos tratamentos; elaboração de folders educativos, de manual de normas e rotinas de atendimento ao paciente oncológico e álbum seriado de orientaçôes para a prevenção de radioepitelite; consulta de enfermagem ao paciente em tratamento radioterápico; aplicação do processo de enfermagem no atendimento ao paciente internado; apoio psicológico; contra-referência dos pacientes aos municípios de origem com orientação dos cuidados pós-alta. Essa parceria nos leva a concluir que o trabalho de integração ensino-serviço para o atendimento ao paciente com câncer possibilita despertar no aluno as funções, as habilidades e a abrangência de competência da enfermagem na área oncológica; também possibilita orientaçôes adequadas e suporte psicológico por meio da consulta de enfermagem, quando os pacientes e familiares manifestam suas necessidades; busca resgatar, ainda, a cidadania e elevar a auto-estima desses pacientes, ao mesmo tempo em que desenvolve o acolhimento, a humanização da assistência na busca efetiva de soluçōes em torno da defesa da vida desses pacientes.
\end{abstract}

E-mail: ccastro25@ig.com.br 